\title{
La reestructuración del sector agropecuario en Chile
}

$\mathrm{A}$ partir de 1973, la economía y la agricultura chilena experimentaron un largo proceso de reformas estructurales y de apertura al exterior, fuertemente centradas en la ideología neoliberal. Hasta ese año, el sector agropecuario chileno se había mantenido inserto en el proceso de industrialización vía sustitución de importaciones iniciado por este país desde la década de los años treinta. Uno de los efectos de este modelo sobre la economía chilena, como en muchos países de América Latina, fue el estancamiento relativo que experimentó la agricultura. Este fenómeno, derivado de las políticas de fomento a la industrialización, originó fuertes distorsiones en la rentabilidad de las actividades agropecuarias y una pérdida de importancia en términos de su participación en el producto nacional.

Sin embargo, la inexistencia de esquemas eficientes para la capitalización del sector industrial se combinó con la falta de un sector agrícola más dinámico que pudiera responder a los requerimientos del mismo desarrollo. Con respecto a la agricultura, la disminución de la inversión pública en el campo provocó, entre otras cosas, un descenso en la producción y una agudización de la migración campo-ciudad, lo que a su vez estimuló el desempleo en las áreas urbanas y la incapacidad de satisfacer la creciente demanda de alimentos. ${ }^{1}$

Esta incapacidad del sector agropecuario para satisfacer adecuadamente la demanda de alimentos ocasionó serios problemas de abastecimiento en los centros urbanos, incidiendo cada vez más en el nivel de vida de la población en general. Esta situación, que se torna crítica a comienzos de la década de los años sesenta, sería enfrentada por el gobierno con la implementación de un programa de reforma agraria con el fin de estimular la producción.

* Investigador del Departamento de Estudios del Pacífico de la Universidad de Guadalajara.
Para entonces, se consideraba ya al sector agropecuario como el soporte básico para avanzar en el proceso de industrialización, debido a que su estancamiento presionaba al gobierno a un mayor desvío de recursos derivado de las importaciones de alimentos, además de otros efectos sociales como el desempleo urbano y el surgimiento de cinturones de pobreza en la periferia de las ciudades, generados por las oleadas de campesinos.

En 1964, con la promulgación de la Ley de reforma agraria, se dio un fuerte impulso a las actividades agrícolas al modificarse el régimen de propiedad de la tierra. Esta medida permitió expropiar los predios considerados poco productivos y de una superficie mayor a 80 hectáreas de riego. Además, se aplicó un programa integral de transformación y modernización del sector agropecuario que contemplaba, entre otras políticas, la operación de planes de fomento para los subsectores forestal, frutícola y ganadero. ${ }^{2}$

Con el arribo de Salvador Allende a la presidencia en 1970, se profundizó el programa de reforma agraria, al eliminarse las restricciones legales en relación con la superficie mínima de los predios sujetos a expropiación, situación que propició un clima de fuerte inseguridad en el campo. Además de estos cambios en la tenencia de la tierra, se introdujo la política de control sobre los precios agrícolas y se impusieron fuertes restricciones sobre las importaciones agrícolas, derivando todo ello en un mayor desabasto de los principales productos básicos.

Pero también hubo cambios significativos a favor de la organización sindical campesina y del movimiento cooperativo en las formas de asignación de los recursos financieros hacia el sector, así como en el desarrollo de la infraestructura agroindustrial. Sin embargo, la crisis generalizada en el plano político y 
económico terminó por frustrar la incipiente experiencia de modernización de la agricultura que se había iniciado años atrás.

De esta forma, previo al arribo del régimen militar de Pinochet en 1973, el sector agropecuario chileno se encontraba entre los más regulados y sujetos a controles por parte del gobierno. Además, el programa de reforma agraria había dado como resultado que cerca de la mitad de la tierra agrícola fuera expropiada y que las unidades de producción rural más grandes prácticamente desaparecieran.

A partir de 1973, la política agropecuaria se orientó a establecer determinadas condiciones previas para la aplicación de una nueva estrategia de desarrollo: generar un renovado escenario de confianza entre los productores medianos y grandes, y desarticular el movimiento campesino apoyado por el gobierno de Salvador Allende. En el terreno político, el primer paso consistió en devolver a sus antiguos propietarios las tierras que les habían sido expropiadas con la reforma agraria y, en segundo lugar, se establecieron una serie de disposiciones legales para debilitar a los sindicatos y organizaciones campesinas, complementadas con una fuerte represión social. Mientras que en el campo económico, se impulsó la liberalización comercial y del mercado agropecuario y se fomentaron las exportaciones agropecuarias. $^{3}$

\section{La primera fase de las reformas, de} 1974 a 1983

Con la nueva estrategia económica para la liberalización de la agricultura, el gobierno militar suprimió una serie de importantes restricciones sobre la producción agrícola. Las reformas más importantes en esta primera fase incluyeron la restitución de las tierras expropiadas y el estímulo al mercado de ésta, la disminución de la intervención del sector público en la agricultura, la privatización de los mercados de insumos y de productos, la liberalización del comercio agropecuario y la eliminación de los controles sobre los precios agrícolas.

Fue así como se devolvió a sus antiguos propietarios la tierra expropiada por la reforma agraria, se suprimieron las bandas de precios agrícolas, el gobierno se retiró de las actividades relacionadas tanto con la comercialización agrícola como con la producción y distribución de insumos agropecuarios, se eliminaron los subsidios a los fertilizantes, el crédito rural, maquinaria y otros bienes de capital. De igual

Cuadro 1

La política agrícola hasta 1973

\begin{tabular}{|l|l}
\hline \multicolumn{1}{|c|}{ Medidas de política más importantes } & \multicolumn{1}{c}{ Instrumentos } \\
\hline Distribución de la tierra & Ley de reforma agraria \\
\hline Planes de fomento por subsectores & $\begin{array}{l}\text { Plan frutícola, Plan ganadero sur, creación de empresas agroindustriales verticales, } \\
\text { financiamiento público (tasas de interés preferenciales). CORFO, INDAP. }\end{array}$ \\
\hline Intervención de mercados agropecuarios & $\begin{array}{l}\text { Fijación de precios agrícolas, control de la producción agrícola, control de exportaciones e } \\
\text { importaciones, excenciones de impuestos y aranceles. ECA, Banco Central. }\end{array}$ \\
\hline Desarrollo de infraestructura de riego & $\begin{array}{l}\text { Construcción de grandes embalses y redes de riego, incorporación de 600 mil hectáreas de } \\
\text { riego. }\end{array}$ \\
\hline Fomento a la pequeña agricultura & Programas de asistencia técnica y crédito a campesinos. INDAP. \\
\hline Fomento a la innovación tecnológica & $\begin{array}{l}\text { Apoyo a la investigación agropecuaria, financiamiento a las universidades e institutos } \\
\text { tecnológicos. INIA. }\end{array}$ \\
\hline Fomento a organizaciones de productores & $\begin{array}{l}\text { Apoyo a los sindicatos y organizaciones campesinas, fomento a la actividad cooperativa. } \\
\text { Leyes de fomento cooperativo. }\end{array}$ \\
\hline Participación del sector público & ODEPA, CORA, INDAP, INIA, IER, ICIRA, IDI, etc. \\
\hline Fuente: Belfor Potila, “La politica agricola en
\end{tabular}

Fuente: Belfor Portilla, "La política agrícola en Chile: lecciones de tres décadas", División de Desarrollo Productivo y Empresarial,

Naciones Unidas, Santiago de Chile, febrero de 2000. 
forma, se modificaron las leyes en materia laboral procurando una mayor flexibilidad en el mercado de trabajo. ${ }^{4}$

Fomento al mercado de la tierra rural

La tenencia de la tierra fue probablemente el aspecto de mayor interés en los primeros años de la reforma del sector. Para 1973, año en que se detuvieron las expropiaciones, producto de la reforma agraria impulsada por Salvador Allende, cerca del 65 por ciento $-730 \mathrm{mil}$ hectáreas- de la tierra irrigada y 50 por ciento -9.2 millones de hectáreas- de la tierra agrícola total estaba en manos del sector público. ${ }^{5} \mathrm{El}$ anterior gobierno había favorecido la conformación de grandes unidades agrícolas bajo la forma de cooperativas y de granjas de propiedad estatal, desalentando a la propiedad privada en la agricultura.

Para 1974 se inició un proceso de distribución y restitución de la tierra, conocido como "regularización de la reforma agraria", estableciéndose granjas familiares individuales con una superficie máxima de 8 hectáreas de tierra irrigada o su equivalente. Esto permitió asignar títulos de propiedad a casi $110 \mathrm{mil}$ pequeños productores y a 70 mil indígenas, pero también se restituyó cerca del 30 por ciento de la tierra expropiada a sus antiguos propietarios. Paralelamente, el gobierno alentó la con-

Fuente: B. Portilla, op. cit, 2000.
A partir de 1973, la política agropecuaria se orientó a establecer determinadas condiciones previas para la aplicación de una nueva estrategia de desarrollo: generar un renovado escenario de confianza entre los productores medianos y grandes, y desarticular el movimiento campesino apoyado por el gobierno de Salvador Allende figuración de un mercado libre de la tierra al autorizar la venta y renta de parcelas y derechos asignados sin restricción alguna, posibilitando el acceso a ella a la inversión privada no ligada tradicionalmente a la agricultura. ${ }^{6}$ En 1978, se decretó una nueva ley que impedía las expropiaciones de la tierra por parte del gobierno.

Como se podrá observar en el cuadro 2, los intentos por alcanzar una mejor distribución de la tierra, es decir, un cambio estructural en la propiedad de la tierra, constituyó una de las bases fundamentales para el desarrollo de una agricultura de tipo empresarial más acorde a los requerimientos del mercado, basada en la productividad y la rentabilidad más que en el uso extensivo del suelo facilitado por el tamaño de los predios, aunque el entorno de restricciones crediticias y de falta de asistencia técnica seguían siendo los principales obstáculos en este proceso.

Los anteriores cambios en la distribución de la tierra se tradujeron en un aumento en el número de minifundios; como resultado de las subdivisiones de las parcelas asignadas y de parcelaciones en comunidades indígenas se elevó

también el número de explotaciones familiares. Pero, por otro lado, se multiplicaron las unidades de tamaño $m$ e d i o derivadas de

\begin{tabular}{|c|c|c|}
\hline \multicolumn{3}{|c|}{ (valores en por cientos) } \\
\hline Tamaño en has. & 1965 & 1979 \\
\hline Menores de 5 & 9.6 & 14.6 \\
\hline De 5 a 20 & 12.7 & 40.3 \\
\hline De 20 a 80 & 22.5 & 26.9 \\
\hline Mayores de 80 & 55.2 & 18.2 \\
\hline Total & 100 & 100 \\
\hline
\end{tabular}


la restitución de predios y se abrió el camino para la conformación de grandes empresas agroindustriales. $^{7}$

\section{La liberalización de los mercados agropecuarios}

En 1970 había una excesiva intervención del gobierno en la agricultura, la cual se manejaba a través de dependencias estatales vinculadas directamente con las actividades agropecuarias. Para 1974, con los radicales cambios emprendidos en el sector público, se eliminaron todos los monopolios estatales en la comercialización interna y externa de insumos y productos agropecuarios, algunos como la Empresa de Comercio Agrícola (ECA) desaparecieron, mientras que otros como la Industria Azucarera Nacional (IANSA) fueron privatizados.

Se esperaba que el libre juego de la oferta y la demanda, en condiciones de apertura, permitiría una eficiente asignación de los recursos mediante la liberalización de precios de los insumos y productos agrícolas. La idea era que, a mediano plazo, se diera una alineación de los precios internos con los precios internacionales, supuestamente no subsidiados. No obstante, en el caso de algunos rubros que se consideraban sensibles o estratégicos, se mantuvo cierta protección. Al comienzo del gobierno militar, por razones estratégicas y de seguridad derivadas del entorno político adverso, aunadas a presiones de sectores empresariales agrícolas vinculados al régimen, se determinó dar un trato especial para algunos alimentos considerados básicos. Se argumentaba que era necesario asegurar una proporción importante del abastecimiento interno de estos, lo cual implicaba una contradicción con la política económica neoliberal adoptada.

De esta forma, entre 1974 y 1978 , ECA mantuvo el control de la comercialización interna y externa de productos como trigo, maíz, arroz, papas, carne y leche, entre otros. La intervención del gobierno tendió a disminuir gradualmente hasta llegar a su desaparición en
1981. Únicamente el trigo y las oleaginosas quedaron bajo un sistema de precios de referencia, mientras que la remolacha quedó sujeta a un precio fijado en dólares y manejado bajo contrato. Este mecanismo de control sobre los precios agrícolas, también conocido como bandas de precios, mediante el cual se fijaba un precio mínimo y un máximo para los distintos productos agrícolas, fue eliminado en 1979 a petición de los propios productores debido a que los precios internacionales habían rebasado a los precios máximos internos. Con ello se eliminaba la más importante medida de intervención estatal directa dentro de la política agrícola.

Respecto al mercado de insumos se siguió la misma orientación, en términos de eliminar paulatinamente los mecanismos vigentes de transferencias a favor del sector agropecuario. Esto implicó una drástica disminución de los subsidios a los insumos derivados de líneas de crédito preferenciales con tasas de interés menores a las del mercado. Adicionalmente, se suprimieron las exenciones y reducciones de impuestos en las importaciones de insumos como fertilizantes, semillas y pesticidas entre otros, lo cual provocaría importantes alzas en los costos de producción.

En congruencia con la liberalización del comercio se fueron privatizando las principales empresas estatales que tenían infraestructura y que operaban en la regulación de los diversos mercados agrícolas, como la Empresa Nacional de Frigoríficos (ENAFRI), la Sociedad de Comercialización Agropecuaria (SOCOAGRO), la Empresa Nacional de Semilla (ENDS), entre otras. Este retiro de las actividades agropecuarias por parte del Estado se da en un proceso más amplio de privatizaciones. Cabe subrayar que para 1980 quedaban bajo control del gobierno sólo 43 de las 500 empresas que se habían estatizado o intervenido anteriormente. ${ }^{8}$

\section{La política del crédito}

En 1974, a pesar de que la agricultura contribuía con 10 por ciento del Producto Interno Bruto (PIB) absorbía, por otro lado, alrededor de 30 
por ciento del crédito total de las instituciones financieras. La banca estatal otorgaba créditos a tasas de interés por debajo de las tasas de mercado y fungía como proveedor de fertilizantes y otros insumos, es decir, podía vender insumos agrícolas a precios menores a los precios de mercado. Además, se eximió del pago de impuestos a las importaciones y se otorgaron redescuentos en los créditos contraídos.

A partir de ese mismo año todas estas concesiones quedaron suprimidas al desaparecer el redescuento en las deudas y las líneas de crédito preferenciales. Con ello, el gobierno fue reduciendo la influencia de los grupos de presión, quienes se habían visto favorecidos con préstamos blandos siempre que enfrentaban condiciones desfavorables. No obstante, la banca estatal mantuvo algunas líneas de crédito para actividades agrícolas, pero a tasas de interés comerciales y con criterios más selectivos.

Paralelamente, entre 1974 y 1981, se modificó radicalmente la importancia del capital privado como fuente de financiamiento para la agricultura, ya que éste pasó de 9 a 76 por ciento del crédito para el sector agropecuario. Esto significa que en un período de tiempo relativamente corto, los productores agropecuarios, además de tierra, contaron con las fuentes de financiamiento suficientes para emprender todo un proceso de transformación del agro chileno.

Sin embargo, este contexto de abundantes flujos financieros internos y externos de fácil obtención provocó un acelerado proceso de endeudamiento que comprometía fuertemente el patrimonio de los productores, particularmente de los medianos y pequeños, volviéndose cada vez más vulnerables ante cualquier fluctuación de los mercados agropecuarios nacional e internacional o ante cualquier cambio en las expectativas económicas del país. En este período, el monto total de los créditos había pasado de 14 a 91 por ciento del PIB agrícola. ${ }^{9}$

Esta situación, que se manifestaba también en otros sectores económicos, desató una crisis generalizada, colapsando el sistema financiero privado del país y obligando al gobierno a intervenir los principales bancos con un costo equivalente a 20 veces el PIB agropecuario chileno del año 1983. Con ello, el supuesto de que el endeudamiento privado era más eficiente que el público quedó en entredicho. El Banco Central se vio en la necesidad de apoyar tanto a los mayores deudores como a los grandes bancos privados, de tal forma que quienes tenían obligaciones en dólares fueron beneficiados con un tipo de cambio subsidiado y con el establecimiento de un esquema para convertir deudas en dólares a moneda nacional. ${ }^{10}$

Para principios de los años ochenta era innegable que la apertura comercial y la falta de control en el rápido crecimiento de los flujos de financiamiento habían conducido a un insostenible déficit en la cuenta corriente cercano a 17 por ciento del PIB, en tanto que la deuda externa se había elevado hasta alcanzar 46 por ciento del PIB. ${ }^{11}$

\section{El fomento a las actividades forestales}

El nuevo gobierno decidió otorgar un decidido impulso al desarrollo del subsector forestal mediante grandes subsidios a las plantaciones forestales. Esto se traduciría en un acelerado crecimiento de la superficie forestal, al pasar de 400 mil a 1 millón de hectáreas entre 1974 y 1981, y sentó las bases para el posterior auge de las exportaciones forestales. Para 1997, 80 por ciento de las plantaciones forestales se encontraba en predios mayores de 200 hectáreas y 60 por ciento en predios de más de 1000 hectáreas, presentándose una fuerte concentración de esta actividad en pocas pero grandes empresas verticalmente integradas. Paulatinamente, las actividades forestales se fueron extendiendo a suelos ganaderos y agrícolas cuyos ex propietarios pasaron de pequeños campesinos a trabajadores asalariados. $^{12}$ 


\section{El fomento a la innovación y desarrollo tecnológicos}

La generación de tecnología agropecuaria estaba básicamente en manos del Instituto de Investigaciones Agropecuarias (INIA), mismo que había sido fundado en 1964. Para mediados de los años setenta, este último manejaba 90 por ciento de los recursos destinados por el Estado para los servicios de investigación y extensión agropecuaria. Al igual que en otros países, se buscaba aumentar la oferta de alimentos básicos, considerada como insuficiente, mediante la generación y utilización de paquetes tecnológicos de alto rendimiento que permitieran incrementar la productividad. Hasta 1973, el INIA proveyó a los productores de conocimientos e insumos prácticamente sin costo alguno. Además, se creó una red de centros experimentales que desempeñaron una función fundamental en el desarrollo tecnológico del campo.

Con el arribo del gobierno militar se determinó que los productores deberían buscar por sus propios medios el acceso a las tecnologías para modernizar sus sistemas de producción, por lo que ahora sólo se financiarían aquellas actividades con bajo nivel de productividad y competitividad. Fue así como el INIA suspendió sus apoyos a las actividades pecuarias y redujo la investigación frutícola sólo a aquellos ámbitos que el sector privado no podía o no quería abordar, privilegiando la adaptación de tecnología del exterior. No obstante, dicho organismo continuó con los trabajos de mejoramiento genético, básicamente de cereales, leguminosas, papas y, en menor grado, de hortalizas y forrajes, así como con los programas de investigación vinculados al manejo agronómico de los cultivos, control de plagas y fertilidad de los suelos, cuyos resultados y difusión sería de gran importancia para el mejoramiento de la producción agrícola.

A partir de 1979 los recursos de INIA comenzaron a disminuir significativamente hasta alcanzar sólo 40 por ciento del presupuesto total anual para 1989, viéndose en la necesidad de obtener recursos propios mediante la venta de sus servicios. En materia de transferencia de tecnología se suprimieron los servicios del Servicio Agrícola y Ganadero (SAG) y de la Corporación de la Reforma Agraria (CORA), manteniéndose solamente los programas del Instituto de Desarrollo Agropecuario (INDAP) bajo la modalidad de asistencia técnica privada a través de un subsidio a la demanda que iría descendiendo progresivamente.

Paralelamente, el INDAP mantuvo una línea de asistencia técnica directa asociada al otorgamiento de créditos. Entre 1978 y 1982 se otorgó asistencia técnica a 10 mil productores en promedio por año, lo cual representaba una cobertura de apenas 4 por ciento del total, debido principalmente a la baja calidad en la asistencia y a la falta de interés por parte de los productores para cubrir aunque fuera una parte del costo de los servicios. ${ }^{13}$

Fue así como, a principios de los años ochenta, la intervención del gobierno en las actividades agropecuarias se redujo básicamente a la investigación y transferencia de tecnología, la inspección sanitaria, el financiamiento a los pequeños productores, a una mínima intervención en la comercialización de algunos productos básicos y a promover las plantaciones forestales. Este alineamiento de la política agrícola al marco de la política macroeconómica, se vería modificado como consecuencia de la creciente diferenciación en el dinamismo de las regiones y de los subsectores agrícolas tradicional y moderno, y ante la necesidad de programas sociales que permitieran contrarrestar las presiones derivadas de la recesión económica que comenzaba a gestarse.

\section{La segunda fase de las reformas, 1984- 1998}

El paulatino deterioro en las condiciones económicas internas, como consecuencia de la crítica situación del sistema financiero y de una revalorización del tipo de cambio, entre otros factores, se vio agravado con la crisis de la deuda de 1982 que se inició en México y se propagó a la mayor parte de los países de la región. Esta situación condujo a un viraje obligado en la 
política económica en general y del sector agropecuario en particular, y se tradujo en la aplicación de medidas e instrumentos que contradecían en cierta forma a la lógica neoliberal precedente. El rescate del sistema financiero, la intervención de los mercados agropecuarios y el establecimiento de una serie de subsidios y mecanismos de fomento por parte del Estado, dan cuenta de ello. De igual forma, el proceso de privatización de grandes empresas estatales, llevado a cabo con facilidades especiales y algunas irregularidades en las adjudicaciones, escapaba a un transparente funcionamiento del mercado y de la doctrina vigente.
A pesar de lo anterior, las medidas de política, aunque con altibajos, vinieron a consolidar el modelo exportador chileno con un tipo de cambio al alza y manteniendo la apertura externa. En efecto, en materia de aranceles por ejemplo, después de la decisión de elevarlos de 10 a 35 por ciento para 1984 , estos descendieron a 15 por ciento en 1988 , llegando a 11 por ciento para 1998. Por su parte, el tipo de cambio real subió 25 por ciento en 1985,13 por ciento en 1986, hasta alcanzar en 1988 un nivel superior en 70 por ciento al registrado a principios de los años ochenta. ${ }^{14}$ En cuanto al sector agropecuario, se describen a continuación los cambios más importantes en la política agrícola con respecto al período precedente:

\section{Cuadro 3}

Principales cambios en la política agrícola entre 1973 y 1983

\begin{tabular}{|c|c|}
\hline Impulso al mercado de la tierra & $\begin{array}{l}\text { Restitución de tierras expropiadas, distribución de predios individuales, } \\
\text { disposiciones legales que impiden la expropiación de la tierra. Leyes que disuelven } \\
\text { comunidades indígenas. }\end{array}$ \\
\hline Liberalización de mercados agropecuarios & $\begin{array}{l}\text { Se liberan los precios a excepción de la remolacha. Se eliminan bandas de precios } \\
\text { en trigo y oleaginosas en 1979. Menor intervención en la comercialización. } \\
\text { Disminuyen los aranceles y se fomentan las exportaciones no tradicionales. }\end{array}$ \\
\hline Retiro del sector público en la agricultura & $\begin{array}{l}\text { Disminuyen los apoyos del gobierno, privatización de empresas estatales IANSA, } \\
\text { SOCOAGRO, AOCORA, ENDS, VINEX, ENAFRI, COMARSA, etc. }\end{array}$ \\
\hline Infraestructura de riego & Se detiene la construcción de nuevas obras. \\
\hline Fomento a la pequeña agricultura & Crédito a tasas de interés de mercado. Se reducen programas. \\
\hline Innovación tecnológica & $\begin{array}{l}\text { Disminuye el financiamiento, se crean fondos concurrentes y se promueve la } \\
\text { inversión privada. }\end{array}$ \\
\hline Fomento a silvicultura & Subsidio a plantaciones forestales. \\
\hline $\begin{array}{l}\text { Derechos laborales y organizaciones de } \\
\text { productores }\end{array}$ & $\begin{array}{l}\text { Se coarta la posibilidad de realizar reuniones, negociaciones colectivas y huelgas } \\
\text { laborales. Se impide otorgar tierra a dirigentes sindicales. Se disuelven las } \\
\text { Confederaciones Sindicales Campesinas y se promueve la desintegración de } \\
\text { cooperativas campesinas. }\end{array}$ \\
\hline \multicolumn{2}{|c|}{ Principales cambios en la política agrícola entre 1984 y 2000} \\
\hline $\begin{array}{l}\text { Ajustes en la política agrícola después de } \\
\text { la crisis de 1982/1983 }\end{array}$ & $\begin{array}{l}\text { Se interviene nuevamente en la comercialización. Creación de COPAGRO Y } \\
\text { COTRISA. Bandas de precios en trigo, azúcar y aceites. Sobretasas a } \\
\text { importaciones de lácteos. Subsidio a la inversión privada en obras de riego. }\end{array}$ \\
\hline Mercado de tierras & Programa de regularización de títulos de propiedad rural. \\
\hline Estabilización de precios & $\begin{array}{l}\text { Se mantienen bandas de precios para atenuar cambios en los precios } \\
\text { internacionales en trigo, harina de trigo, azúcar y aceite. Continúa intervención en } \\
\text { la comercialización de trigo y arroz. Se crean bolsas de productos agropecuarios y } \\
\text { centros de acopio para pequeños productores. }\end{array}$ \\
\hline Política de comercialización & $\begin{array}{l}\text { Se reglamentan características físicas y químicas para la comercialización de trigo, } \\
\text { maíz, arroz y carne. Se crea un sistema de información productiva por rubros y } \\
\text { regiones. }\end{array}$ \\
\hline Servicios de información & $\begin{array}{l}\text { Se crean sistemas de información de precios regionales y de mercado para la } \\
\text { pequeña agricultura. }\end{array}$ \\
\hline Inserción en los mercados internacionales & $\begin{array}{l}\text { Se firman acuerdos comerciales con México, Venezuela, Bolivia, Colombia, } \\
\text { Ecuador, Mercosur y Canadá. }\end{array}$ \\
\hline
\end{tabular}

Fuente: B. Portilla, op. cit., 2000. 


\section{Estabilización de los precios}

Como parte de los esfuerzos del gobierno para reactivar la agricultura, se aplicó una política tendiente a atenuar el efecto de las fluctuaciones de los mercados agrícolas internacionales sobre los precios relativos de algunos productos considerados como sensibles. Se buscaba generar un panorama de mayor confianza y estabilidad en la producción agrícola, de modo que los productores agrícolas tuvieran asegurados, previo a la siembra, los precios mínimos que regirían al momento de las cosechas.

Los instrumentos utilizados por el gobierno serían el mecanismo de las bandas de precios para asegurar la oferta de alimentos y precios estables en productos como trigo, azúcar $\mathrm{y}$ aceite. Adicionalmente, se intervino de nuevo en la comercialización del trigo como medida de apoyo a los productores, especialmente durante la caída de los precios internacionales de mediados de los años ochenta, y se establecieron medidas antidumping para las importaciones de arroz, maíz, frutas, hortalizas, leche en polvo y descremada. El efecto de estas medidas fue que los productos agropecuarios de mayor importancia recibieron durante algunos años un nivel de protección nominal superior al arancel general uniforme. ${ }^{15}$

Durante la década de los años noventa se procuró fortalecer la transparencia de los mercados internos mediante diversas iniciativas enfocadas a una mayor difusión de información sobre los precios agrícolas, los cuales son monitoreados en forma permanente por la Oficina de Estudios y Políticas Agrícolas (ODEPA). A su vez, el desempeño de los distintos subsectores es evaluado a través de comisiones especializadas, las cuales convocan a los distintos agentes involucrados para evaluar la problemática y aportar soluciones.

\section{Fomento a las exportaciones}

A partir de 1985, como medida para estimular las exportaciones, se creó un mecanismo mediante el cual se reintegraba a los exportadores los derechos de importación pagados por materias primas e insumos utilizados en aquellas exportaciones menores a 2.4 millones de dólares. Inicialmente, la devolución contemplaba 10 por ciento del valor, excluyendo comisiones y cualquier otro gasto de exportación, y suponiendo un componente de importación de 50 por ciento.

En 1987 se incluyó un reintegro de 10 por ciento para los rubros no tradicionales que durante un año se hayan exportado por un monto igual o inferior a 10 millones de dólares, de 5 por ciento para las exportaciones mayores de 10 millones, y de 3 por ciento para las que se ubican a entre más de 15 y menores de 18 millones. De manera adicional, en 1988, se agregó un reintegro de 10 a 15 por ciento por los insumos nacionales exportables incorporados a los productos exportados. El objetivo era corregir la discriminación sobre la industria nacional y sobre el valor agregado de las exportaciones.

Este subsidio, que se mantuvo hasta 1995, se perdía si en un año se rebasaban los montos señalados o si en los últimos tres años calendario, los montos exportados no mostraban aumentos de al menos 1.5 veces el crecimiento promedio del PIB. Entre 1991 y 1995, el monto de este apoyo representó 2 por ciento de las exportaciones agropecuarias, lo cual significa que si bien favoreció el impulso inicial de las exportaciones no tradicionales, su efecto sobre las mismas no fue de gran importancia. ${ }^{16} \mathrm{Como}$ parte del Acuerdo sobre la Agricultura alcanzado dentro de la Ronda Uruguay del GATT, Chile se comprometió a eliminar este programa para el año 2003.

Otro aspecto importante de la política de fomento a las exportaciones fue la preocupación por fortalecer la competitividad en una doble dirección. Por una parte, se procuró apoyar aquellos rubros que se consideraban más vulnerables ante la competencia externa y que son justamente los que recibieron un tratamiento especial en los plazos de desgravación arancelaria, entre ellos los cereales, carne y leche. Por otra, se buscó fortalecer aquellos cuya inserción internacional 
estaba en expansión, o que tenían un potencial exportador, como frutas, hortalizas, semillas y algunos productos agroindustriales como el vino y los productos lácteos.

\section{Apoyo a la infraestructura de riego}

El gobierno también creó una ley de fomento al riego que incluía un programa de subsidios a las obras hidroagrícolas tendientes a aumentar la superficie de riego, así como a mejorar las existentes. Entre 1983 y 1989 se asignaron 34 millones de dólares en beneficio de 900 familias de agricultores y una superficie de riego de alrededor de 300 mil hectáreas. La relación de poco más de 300 hectáreas por agricultor mostraba el alto grado de concentración de los beneficios, mientras que sólo 4 por ciento del total de los recursos se destinó para el único concurso campesino llevado a cabo en dicho período. ${ }^{17}$

No obstante, la aplicación de esta medida de la política agrícola permitió aumentar la inversión pública con participación del sector privado en un aspecto fundamental para mejorar la productividad agrícola. Posteriormente, en 1992, se puso en marcha un programa de rehabilitación y construcción de obras medianas y menores de riego para facilitar el acceso de los pequeños productores, con un monto superior a los 100 millones de dólares. Con este programa se busca impulsar más proyectos de desarrollo agrícola, al incorporarse cerca de $55 \mathrm{mil}$ hectáreas de riego y mejorarse los sistemas de riego en otras 105 mil hectáreas.

\section{Impulso a la tecnología}

La participación del gasto público en investigación y desarrollo, que ascendía a 80 por ciento del total en este campo, fue disminuyendo a partir de 1986 hasta representar 60 por ciento a fines de los años noventa. Sin embargo, esta reducción de los apoyos del Estado, canalizada principalmente a las universidades e institutos tecnológicos, se vio compensada con la creación de fondos concurrentes, mediante los cuales se buscó una mayor participación de la inversión privada en el financiamiento a la investigación.
Actualmente, el gasto en investigación y desarrollo en el sector agropecuario chileno alcanza un punto porcentual del PIB agrícola con modalidades de financiamiento acordes con la tendencia internacional en este sentido. Con ello, se redujeron significativamente los apoyos directos del Estado al INIA y se fortalecieron los fondos concurrentes, los cuales pasaron a representar 20 por ciento del total sectorial. Pero, a diferencia de los países desarrollados donde los aportes por este medio son compartidos por el Estado y el sector privado en partes iguales, en Chile el gobierno es quien aporta los fondos en forma mayoritaria. ${ }^{18}$

Además, esta forma de financiar la investigación y el desarrollo ha privilegiado en mayor medida a las actividades de investigación orientadas a obtener o generar innovaciones tecnológicas a corto plazo en perjuicio de aquellas de carácter más estratégico, las cuales, por el tiempo requerido para su maduración y aplicación, no están en las prioridades de los fondos ni son de interés para el capital privado, lo que ha obligado nuevamente a los organismos públicos a financiar investigaciones a mediano y largo plazo, como las de fitomejoramiento, a través de acuerdos comerciales con la iniciativa privada o a involucrarse directamente en los mercados de insumos, particularmente en la comercialización de semillas mejoradas.

\section{Fomento a la agricultura campesina}

Este punto constituye sin duda uno de los rasgos más distintivos con respecto a las políticas precedentes debido al propósito explícito de apoyar a la pequeña agricultura, así como de mejorar las condiciones de vida de la población rural que, en general, paulatinamente se ha visto marginada del desarrollo e, incluso, deteriorado su nivel de vida.

En Chile, la agricultura campesina representa un conjunto heterogéneo de alrededor de 220 mil familias de pequeños productores, quienes poseen aproximadamente 1.5 millones de hectáreas y aportan la cuarta parte del PIB agrícola. De este total, se estima que sólo entre 100 mil y 120 mil campesinos, 
aun cuando enfrentan una constante presión por asegurar su viabilidad, han podido introducir innovaciones técnicas y de gestión y acceder al financiamiento, para poder insertarse a las nuevas condiciones de los mercados nacional e internacional. Las restantes unidades campesinas marginadas de este proceso, han experimentado un fuerte deterioro de sus escasos recursos, se encuentran bajo la línea de pobreza y sus ingresos provienen en su mayor parte de actividades no agrícolas.

Ante tales circunstancias, las políticas para el primer grupo se han orientado a apoyar una mejor incorporación de la pequeña agricultura a los circuitos comerciales, lo cual no la ha salvado de recibir los efectos más drásticos de las políticas de ajuste y de cambio estructural. En términos generales, además de la asistencia técnica otorgada por el gobierno, las acciones de apoyo se han centrado en el fomento a las organizaciones de productores para una mejor de los pequeños productores en el mercado. De ahí que se haya estado apoyando la conformación de sociedades comerciales, fortaleciendo la capacidad de gestión tanto en los procesos productivos como administrativos.

Con relación a los sectores más desfavorecidos, se ha pretendido que las medidas de política trasciendan el ámbito sectorial para tener un carácter multisectorial. Para ello, se impulsaron una serie de medidas que contemplan metas en materia de educación, salud, vivienda, electrificación, agua potable, vialidad y comunicaciones. En 1997 se aprobó el Plan de desarrollo de zonas de pobreza rural, a partir de políticas aprobadas por un comité integrado por los responsables de la política social. ${ }^{19}$

Sin embargo, parece ser que el problema de la dispersión a que se han sometido los programas e instrumentos públicos, ha conducido a que las acciones tengan realmente poco impacto. Aun así se sigue insistiendo con tales políticas para mejorar el acceso de la población rural a los servicios básicos, reforzándose las orientadas a mejorar sus niveles de ingreso, particularmente de los más pobres. Pese a los avances, las carencias en el medio rural son aún críticas y los indicadores de pobreza e indigencia dan prueba de ello.

Todas estas medidas de la política agrícola significan que el deterioro en la rentabilidad de las actividades agropecuarias de principios de los años ochenta, dio lugar a la aplicación de nuevas y mayores políticas de apoyo del gobierno hacia el sector, mismas que fueron más allá de su función como garante del funcionamiento del libre mercado y de su papel en su lucha contra la pobreza. Una cuestión fundamental de las nuevas políticas del Estado hacia la agricultura fue la búsqueda simultánea de objetivos económicos y sociales.

Con ello, la política agropecuaria, entre otras cosas, puso énfasis en el fortalecimiento de la ruralidad en reconocimiento a la heterogeneidad del campo chileno, lo que implicó la aplicación de medidas para apoyar la inserción de los pequeños productores agrícolas en los mercados, así como de los instrumentos de fomento para las asociaciones y organizaciones de productores. Entre estas medidas destacan programas regionales para el establecimiento de praderas, forestación y manejo del bosque, y de fomento a la comercialización y exportación de productos agropecuarios. $^{20}$

Paralelamente, el gobierno chileno profundizó la apertura comercial mediante el establecimiento de acuerdos comerciales bilaterales y multilaterales con diversos países, entre ellos México, Venezuela, Bolivia, Colombia, Ecuador y el MERCOSUR, con la finalidad de negociar reducciones arancelarias que permitieran disminuir las distorsiones en los precios internacionales de los productos agrícolas, pero sobre todo para lograr una mejor inserción de la agricultura chilena en los mercados internacionales.

\section{Conclusiones}

En resumen, es posible establecer que, a excepción del período 1981-1983, cuando la sobrevaluación del tipo de cambio y las condiciones adversas de los mercados externos 
actuaron en contra del sector, en términos generales, la agricultura chilena se vio beneficiada con la depreciación del tipo de cambio, la apertura comercial y otras medidas desregulatorias, volviendo más funcionales y flexibles los mercados y factores de producción.

Pero también es importante destacar que la intervención del gobierno jugó un papel relevante en beneficio del sector. El histórico papel de un Estado promotor y regulador en los subsectores frutícola, forestal y agroindustrial, los cuales se han caracterizado por su fuerte dinamismo, resultó determinante en su impulso inicial. Posteriormente, las políticas aplicadas en materia de aranceles y de tipo de cambio, vinieron a apoyar de manera fundamental el modelo exportador chileno. Además, las ventajas comparativas que le confieren su posición geográfica, con respecto a otros países, y un ambiente propicio para impulsar la inversión privada y la gestión empresarial, han favorecido una exitosa inserción del sector agropecuario chileno en el mercado internacional.

Sin embargo, los agentes más beneficiados con la desregulación y liberalización de la agricultura chilena han sido principalmente las empresas exportadoras de frutas, como manzanas, uvas y peras; la industria forestal y la agroindustria, particularmente la relacionada con el procesamiento de productos como azúcar, cebada, leche, arroz, uva, carne de cerdo y de aves, jugos y pastas. Lo que pone de manifiesto que en Chile ha habido una importante inserción en los mercados internacionales por parte de los grandes y medianos productores agropecuarios, principalmente de las regiones irrigadas y de aquellas regiones agrícolas con una adecuada capacidad tecnológica y de gestión. ${ }^{21}$

Pero, por otro lado, la misma apertura y reforma estructural del sector agropecuario, han generado un proceso de concentración y exclusión en el medio rural, donde las distintas regiones y productores agrícolas han tenido que adaptarse según sus capacidades y flexibilidad de sus recursos, gestándose dinámicas claramente diferenciadas con notorios desequilibrios en cuanto a rubros, productores y regiones agrícolas. En este sentido, cabe mencionar que los pequeños productores con potencial productivo enfrentan cada vez mayores dificultades para participar en el mercado, pero los más marginados son los minifundistas cuyos ingresos provienen en su mayor parte de actividades no agrícolas y dependen de políticas sociales para mejorar su situación económica.

Además, en el último lapso de los años noventa, la agricultura chilena experimentó un menor dinamismo, básicamente a consecuencia del errático comportamiento de los mercados agrícolas internacionales, lo cual ha debilitado el crecimiento y afectado la rentabilidad de la producción agrícola. Esto significa que si bien la agricultura chilena ha logrado avances importantes en cuanto a productividad y competitividad, también se ha vuelto mucho más vulnerable a las fluctuaciones de los mercados agrícolas internacionales de lo que anteriormente era.

\section{Fuentes}

1 Ver Juan Eduardo Caeymans and Yair Mundlak, "Chilean Agriculture in a Changing Economic Environment", The Bias Against Agriculture, Trade and Macroeconomic Policies in Developing Countries, International Center for Economic Growth and The International Food Policy Research Institute, San Francisco, USA, 1993.

2 Cristian Palma Arancibia, "La política agrícola en la apertura de la economía: el caso de Chile", Naciones Unidas, Oficina Regional de la FAO para América Latina y El Caribe, Santiago de Chile, 1993.

3 Belfor Portilla, "La política agrícola en Chile: lecciones de tres décadas", División de Desarrollo Productivo y Empresarial, Naciones Unidas, Santiago de Chile, febrero de 2000.

4 Ver Eduardo Venezian and Eugenia Muchnik, "Learning from experience of Chile", Agricultural Research in an Era of Adjustment,Policies, institutions and Progress, Economic Development Institute of The World Bank and International Service for National Agricultural Research, Washington, D.C. 1995; Alberto Valdes, "Critical Issues in Sequencing of Reforms: Lessons of Experience from Early Reformers", Agriculture in Liberalizing Economies: Changing Roles for Governments. Proceedings of the Fourteenth Agricultural Sector Symposium, The World Bank, Washington, D.C., 1995; B. Portilla, op. cit., 2000.

5 A. Valdés, op. cit., 1995, p. 62

6 Ver Anne Dubreucq, "Los cambios agrarios en Chile bajo Pinochet, una nueva geografía económica", Agriculturas y campesinados de América Latina. 
Mutaciones y recomposiciones, Fondo de Cultura Económica, México, DF, 1994.

7 Ver Maximiliano Cox, "La agricultura chilena, 19741982", Santiago de Chile, 1983; Alejandro Canales Cerón, "La modernización del agro chileno en los ochenta”, en Agricultura y Desarrollo Regional en la Cuenca del Pacífico, APORTES de la Universidad de Colima, vol. 7, núm. 11, Red Nacional de Investigadores sobre la Cuenca del Pacífico, México, 1996.

8 B. Portilla, op. cit., 2000, p. 14

9 M. Cox, op. cit., 1983.

10 R. French-Davies y O. Rosales, "Chile: crecimiento, empleo y equidad”, CEPAL, 1998.

11 Ibid.

12 B. Portilla, op. cit., 2000, p. 16

13 Ver Eugenia Muchnick, "Subsidios y ayudas al sector agropecuario chileno: integración y competitividad", LC/ R 1724, Unidad de Desarrollo Agrícola, CEPAL, Santiago de Chile, 1997.

14 R. French-Davies y O. Rosales, op. cit., 1998.

15 Ver Luis Felipe Errazuriz y Eugenia Muchnik, "Visión crítica de la agricultura chilena y sus políticas”, Documento de trabajo núm. 245, Centro de Estudios Públicos, Santiago de Chile, 1996.

16 Ibid.

17 E. Muchnik, op. cit., 1997.

18 B. Portilla, op. cit., 2000; A. Valdés, op. cit., 1995;

19 Cristobal Kay, "Globalización, agricultura tradicional y reconversión en Chile", Comercio exterior, agosto de 1996, México, DF; B. Portilla, op. cit., 2000

20 Ibid.

21 Ver CEPAL, "Agroindustria y pequeña agricultura: vínculos, potencialidades y oportunidades comerciales" Oficina Regional de la FAO para América Latina y El Caribe, Santiago de Chile, 1998; C. Kay, op. cit.,1996.

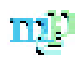

